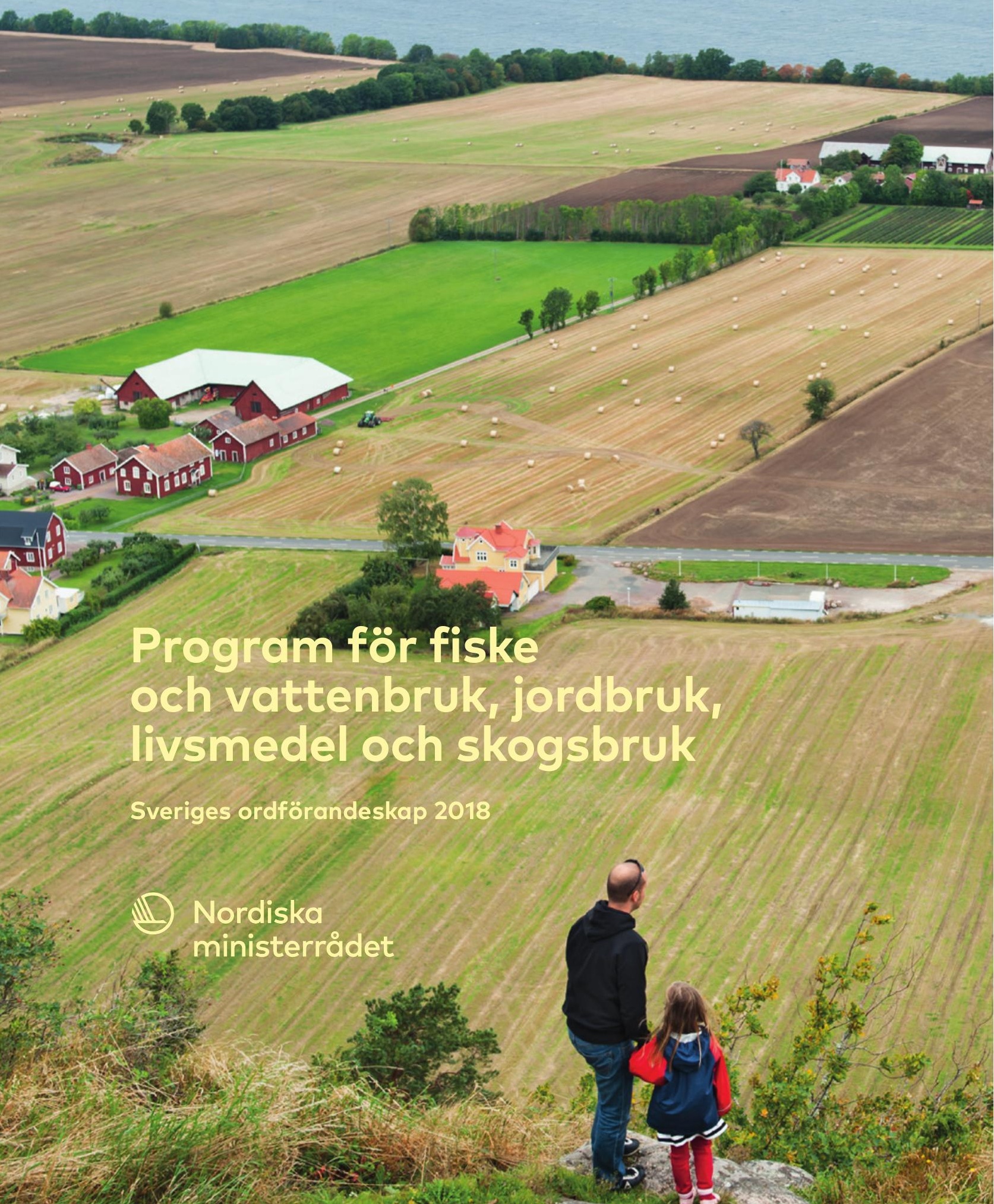




\title{
Program för fiske och vattenbruk, jordbruk, livsmedel och skogsbruk
}

Sveriges ordförandeskap 2018 i Nordiska ministerrådet

\author{
ANP 2017:782 \\ ISBN 978-92-893-5268-O (PRINT) \\ ISBN 978-92-893-5269-7 (PDF) \\ ISBN 978-92-893-5270-3 (EPUB) \\ http://dx.doi.org/10.6027/ANP2017-782 \\ (C) Nordiska ministerrådet 2017 \\ Layout: Gitte Wejnold \\ Omslagsfoto: Julia Sjöberg/Folio
}

\section{Det nordiska samarbetet}

Det nordiska samarbetet är ett av världens mest omfattande regionala samarbeten. Det omfattar Danmark, Finland, Island, Norge och Sverige samt Färöarna, Grönland och Åland.

Det nordiska samarbetet är politiskt, ekonomiskt och kulturellt förankrat och en viktig del av europeiskt och internationellt samarbete. Den nordiska gemenskapen arbetar för ett starkt Norden i ett starkt Europa.

Det nordiska samarbetet vill styrka nordiska och regionala intressen och värderingar i en global omvärld. Gemensamma värderingar länderna emellan bidrar till att stärka Nordens ställning som en av världens mest innovativa och konkurrenskraftiga regioner.

\section{Nordiska ministerrådet}

\section{Nordens Hus}

\section{Ved Stranden 18}

1061 København $\mathrm{K}$

www.norden.org

Ladda ner nordiska publikationer: www.norden.org/nordpub 


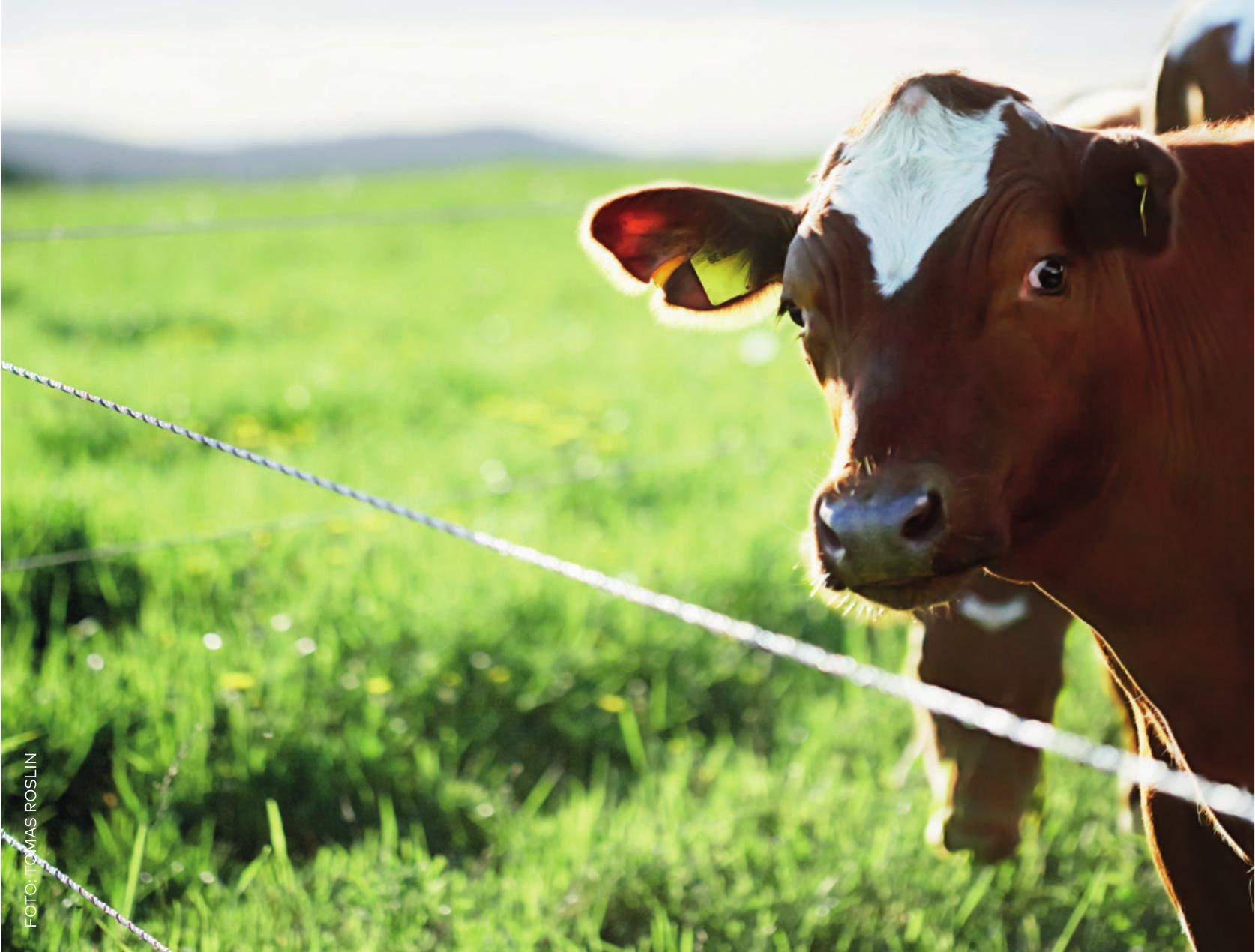


Bästa vänner!

Både som landsbygds- och regionalminister och som tidigare kommunalråd i Haparanda är jag väl medveten om betydelsen av gränsöverskridande regionalt samarbete. För Haparanda/Torneå har det betytt oerhört mycket i form av tillväxt och utveckling att samverka över gränser, så att de två kommunerna i dag utgör en och samma region. Detta är nordiskt samarbete i sin prydnad.

Sverige kommer att leda arbetet inom Nordiska ministerrådet under 2018. Som minister med ansvar för fiske och vattenbruk, jordbruk, livsmedel och skogsbruk ser jag en rad spännande utmaningar framför oss i det nordiska samarbetet, frågor där vi kan göra en skillnad och också visa vår omvärld en bra och hållbar väg framåt.

Utgångspunkten för vårt ordförandeskap är FN:S mål för global utveckling (Agenda 2030), dock nedbrutet till konkreta åtgärder, samt användandet av ny teknik och digitalisering i våra näringar. Inom respektive sektor finns en rad fokusområden. 
Jag vill här bara särskilt nämna frågor som blåoch grön bioekonomi och matsvinn, där vi tar vidare tidigare ordförandeskaps stafettpinne, men också nya satsningar, som digitalisering och beredskapsfrågor. En fortsatt satsning på vår institution NordGen ser jag också som viktig.

Sammanfattningsvis gläder jag mig åt att få möjlighet att leda arbetet inom MR-FJLS 2018 mot framtiden och ett stärkt nordiskt nära samarbetet.

Sven-Erik Bucht Landsbygdsminister

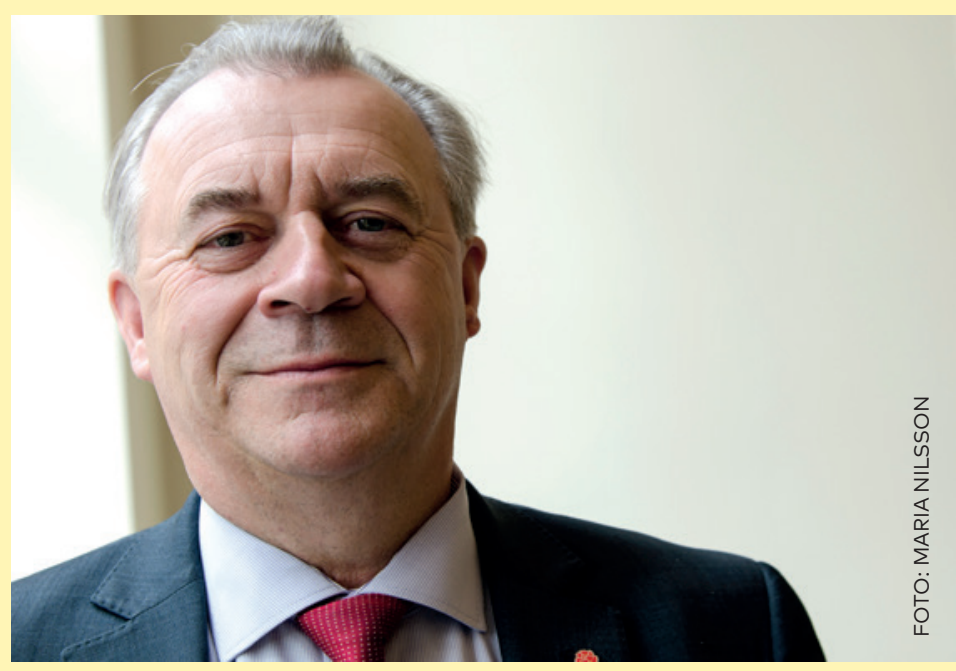




\section{Inledning}

Nordiska ministerrådets för fiskeri och vattenbruk, jordbruk, livsmedel och skogsbruk (MR-FJLS) huvudsakliga uppgifter består i att främja en hållbar användning av naturresurser och genetiska resurser, möta klimatförändringen och dess utmaningar, stödja en hållbar utveckling av kust- och landsbygd samt främja sunda och säkra livsmedel.

Utmaningarna i hållbarhetsarbetet är till stor del globala, men lösningarna företrädesvis lokala. MR-FJLS har i sitt samarbetsprogram för 2017-2020 beslutat att man under perioden ska arbeta för att uppfylla FN:s 17 mål för global utveckling (Agenda 2030). Detta eftersom målen förväntas få en väsentlig betydelse för de nordiska länderna den närmaste framtiden. I samarbetsprogrammet har utveckling av den nordiska bioekonomin och hållbara livsmedelssystem pekats ut som strategiska insatser.

De nordiska länderna har ett omfattande samarbete som bygger på en gemensam historia, kultur och värdegrund. Den snabba förändringen av samhälle, inklusive globaliseringen, ökad konsumtion och produktion, samt klimatförändringar, innebär både utmaningar och möjligheter. Dessa kan mötas av gemensamma nordiska tvärsektoriella initiativ för att skapa förutsättningar för ett gott liv i en hållbar nordisk region och öka nyttan för Norden. De utmaningar som anses vara viktiga för det nordiska samarbetet omfattar behovet av att förbättra den nordiska ekonomins konkurrenskraft, öka medvetenheten om klimatförändringar och ge inspel till viktiga policyfrågor på en europisk nivå. Hela regionen ska leva och det ska vara möjligt att bo och verka på en levande landsbygd. Landsbygdens potential till att utgöra grunden för grön och blå tillväxt ska tas tillvara. Detta förutsätter en hållbar produktion miljömässigt, socialt, och ekonomiskt. För detta ska digitalisering och ny teknik utgöra verktyg.

\section{Fiske}

Inom fiskerisamarbetet är tanken att utifrån ett globalt och lokalt hållbarhetsperspektiv fördjupa arbetet kring vilken roll en blå bioekonomi kan spela för utvecklingen av landsbygden.

De nordiska länderna har höga ambitioner vad gäller att bevara och förvalta havens resurser väl. Detta nordiska synsätt ligger i linje med målen inom Agenda 2030 och bidrar till dess uppfyllnad. Samlade erfarenheter från den globala agendan under 2017 (resultaten från FN:s högnivåkonferens om hållbarhetsmål 14, EU-KOM:s "Our Ocean"-konferens och WTO:s minister- 


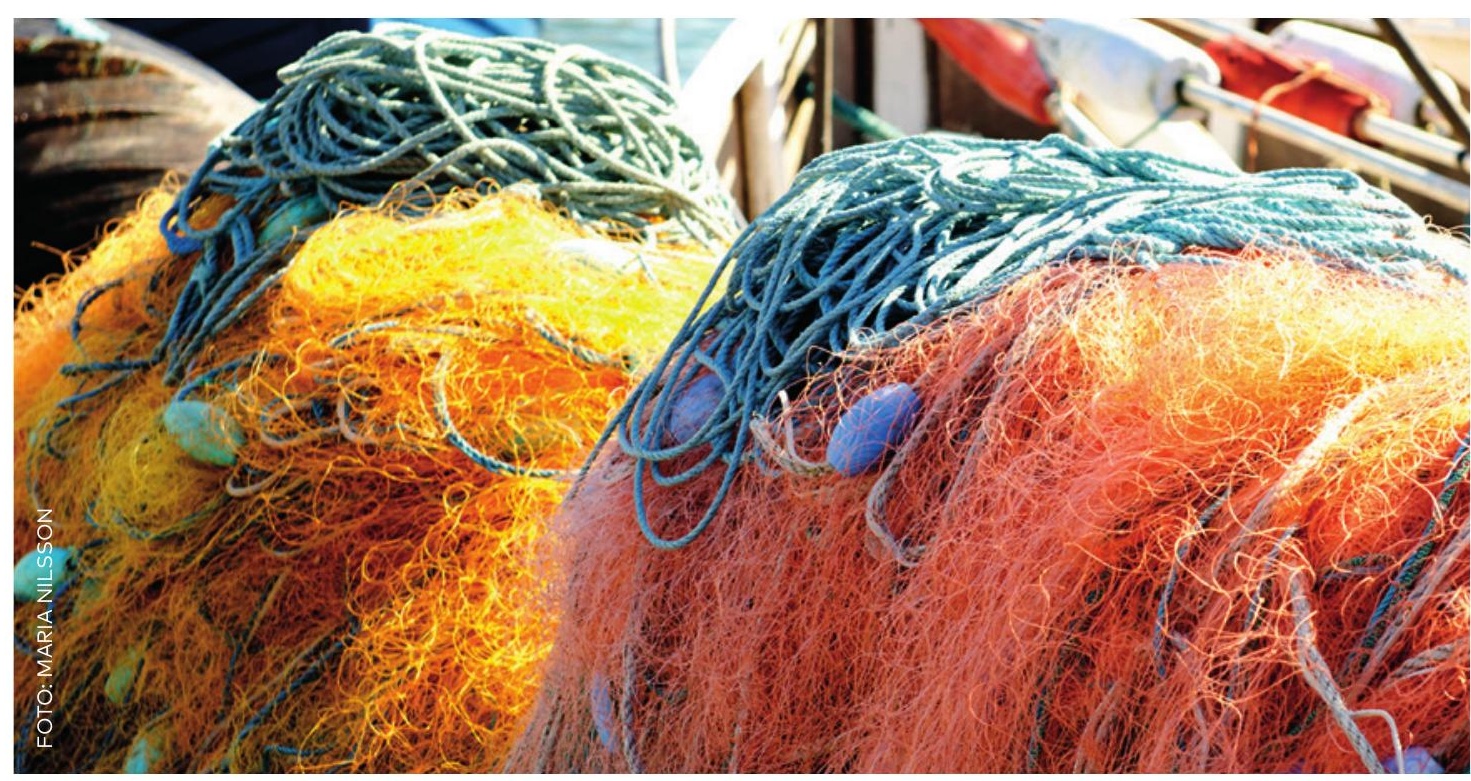

möte om fiskesubventioner) förväntas bidra till att identifiera de behov som kräver lokala lösningar.

Under det svenska ordförandeskapet 2018 kommer fiskerisamarbetet därför fokusera på att förverkliga potentialen inom blå bioekonomi, baserat på den studie och vägkarta som det finska ordförandeskapet tog fram under 2016. I den nordiska vägkartan för blå bioekonomi ingår ett flertal näringar med koppling till vatten såsom fiskeri- och vattenbruksnäringen, beredningsindustrin samt rekreations- och besöksnäringen, vilka samtliga bidrar till lokala lösningar.

Genom att utveckla konceptet - den blå bioekonomin, skapas förutsättningar att föra fram nya produkter och tjänster, producerade utifrån ett hållbart per- spektiv. Med utgångspunkt från blå bioekonomi kommer det svenska ordförandeskapet fokusera på Good Governance som syftar till att uppnå och utveckla hållbar förvaltning som skapar ett livskraftigt och miljömässigt hållbart företagande.

Nya produkter och tjänster som är en central fråga för att skapa förutsättningar för utvecklingen av den blå bioekonomin. Hur kan digitaliseringen skapa företagsutveckling, vidareutveckling av produkter och tjänster som samtidigt skapar attraktivitet inom fiskerinäringen?

Ovanstående fokusområden kommer utgöra teman för de seminarier, möten och projekt som föreslås genomföras under det svenska ordförandeskapet inom ramen för fiskerisamarbetet. 


\section{Jordbruk}

Det nordiska jordbrukssamarbetet ska konkretisera och förverkliga en hållbar utveckling inom den gröna sektorn. Med utgångspunkt från digitaliseringens möjligheter kommer det svenska ordförandeskapet för jordbrukssektorn att fokusera på områdena hållbar förvaltning av biologiska resurser, ökad konkurrensförmåga, resiliens och minskad klimatpåverkan från primärproduktionen samt diversifierad landsbygdsekonomi.

Ett diversifierat näringsliv, grön omställning och ökad konkurrenskraft i nordiska landsbygdsregioner. Hur kan företagen på landsbygden bidra till lösningar på miljö- och klimatutmaningarna? På vilket sätt kan en uppkopplad landsbygd leda till att landsbygdens företag i högre utsträckning deltar i samarbeten och kunskapsutbyten med andra aktörer. Hur kan kommersiell och offentlig service utvecklas genom nya innovativa lösningar och samarbeten?

Digitalisering i jordbruket. Hur kan utnyttjandet av digitaliseringen bidra till en ökad innovationsgrad, effektivare användning av biomassan och en mer resurseffektiv jordbrukssektor? Därigenom även en större klimatnytta från jordbruket?

Utveckling av samarbete kring kunskaps och innovationssystem inom nordiskt jordbruk. Koppling till ICT, jämställdhet och mångfald inom sektorn samt nya företagare.

NordGen och dess verksamhet samt gemensamma nordiska ansträngningar på växtförädlingsområdet är viktiga för utveckling av bioekonomin och uppbyggnad av resilienta livsmedelssystem. Det svenska ordförandeskapet vill under året fokusera på digitaliseringens möjligheter för att underlätta användningen och tillgängligheten till genetiska resurser och för att effektivisera växtförädlingen Livsmedel är en viktig del i den nordiska bioekonomin. Tillsammans med livsmedelssektorn kommer ordförandeskapet arbeta med en hållbar och lönsam utveckling av de nordiska livsmedelssystemen med fokus på effektiv och ansvarsfull produktion av säkra livsmedel och hållbar resursanvändning. En konferens kommer att anordnas om hållbara livsmedelskedjor.

Beredskapsfrågorna har aktualiserats under senare år som en följd av en förändrad omvärldsbild. Utifrån en förstudie om livsmedelsförsörjning i de olika nordiska länderna i en krissituation kommer frågan om potentiellt samarbete inom jordbrukssektorn rörande dessa frågor att tas upp under det svenska ordförandeskapet. 


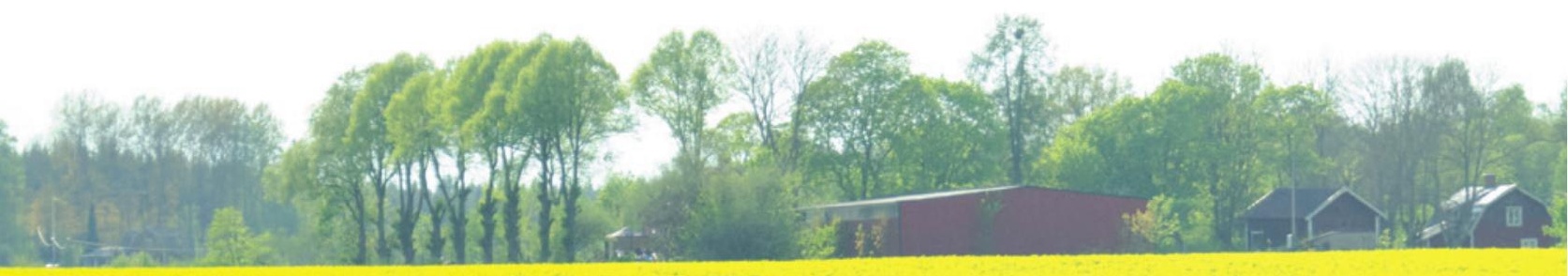

sents

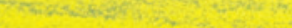

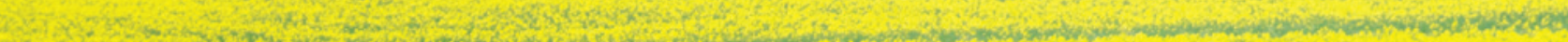

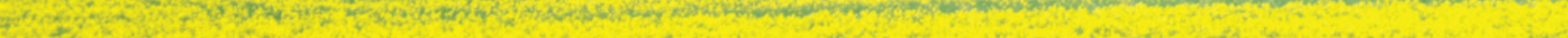

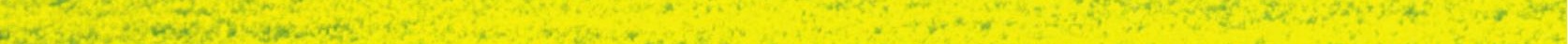

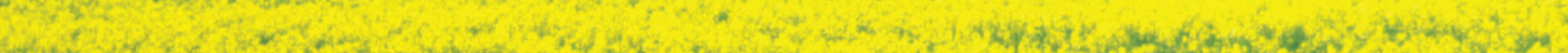

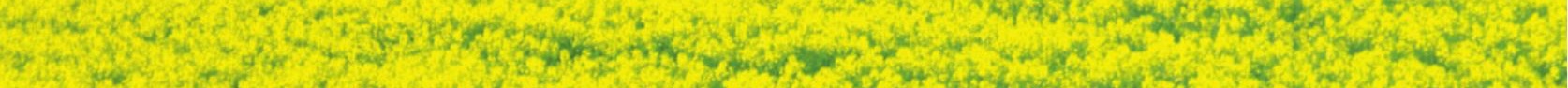
6.

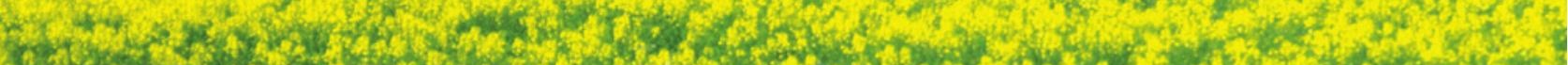
6.7.6. 13.

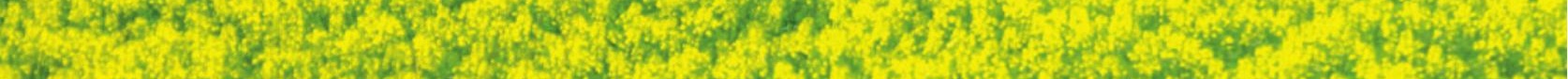

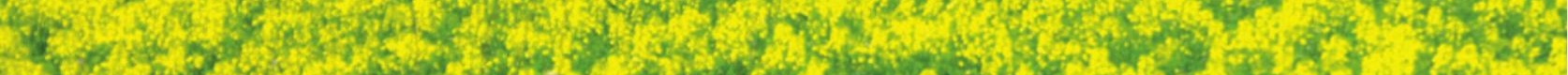

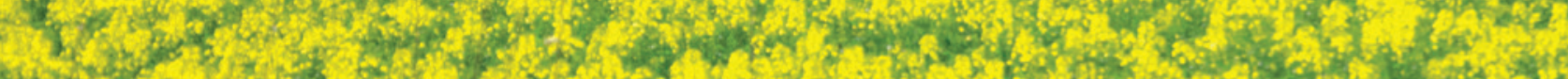
3. C.t.

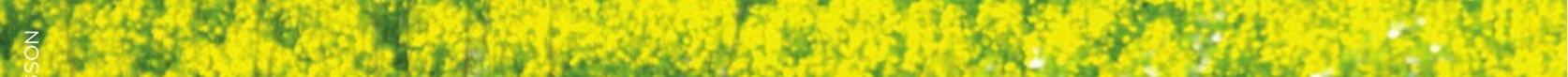

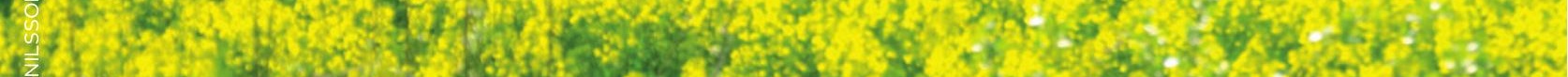

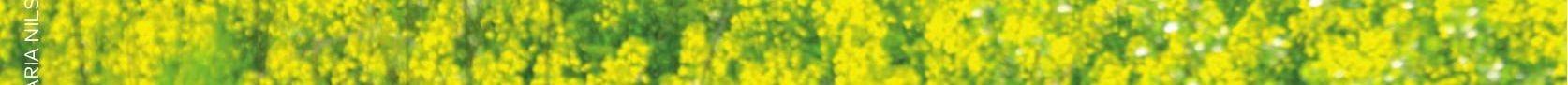

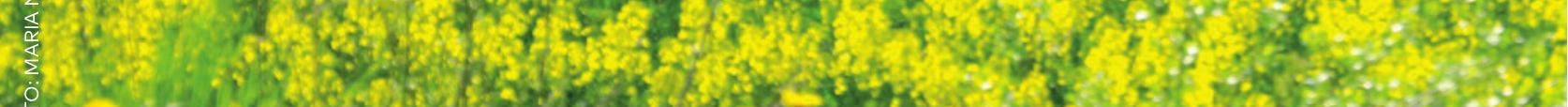
(a) in 2 m. 


\section{Livsmedel}

Det nordiska samarbetet på livsmedelsområdet går till största del ut på att främja hälsosam och säker mat. Det svenska ordförandeskapet vill fortsätta utveckla detta samarbete inom ramen för en hållbar utveckling. Livsmedel och matvanor är direkt eller indirekt relaterade till så gott som alla mål i Agenda 2030 och är därmed viktiga för att nå en social, ekonomisk och miljömässig hållbar utveckling, både i Norden och i resten av världen.

Ett mål i Agenda 2030 som har identifierats som relevant för sektorn handlar om att säkerställa hållbara konsumtions- och produktionsmönster, där vi kan genomföra gemensamma nordiska lösningar för vidare spridning. I Norden har vi goda förutsättningar för att producera livsmedel på ett hållbart sätt med begränsad miljöpåverkan. Det nordiska jordbruket anses resurseffektivt och vi har i jämförelse höga ambitioner både när det gäller djurskydd och djurhälsa. Dagens konsumtion i Norden är däremot långt ifrån hållbar och vi behöver ändra våra konsumtionsmönster. Vi behöver också förhålla oss till situationen utanför Nordens gränser då dagens konsumtion och produktion av livsmedel är ett gränsöverskridande problem. Det är viktigt att vi i Norden fortsätter arbetet med att främja bra och hållbara matvanor och minska på matsvinnet. Livsmedel är en viktig del i den nordiska bioekonomin och därför ska vi fokusera på en hållbar och lönsam utveckling av de nordiska livsmedelssystemen med fokus på effektiv och ansvarsfull produktion av säkra livsmedel och hållbar resursanvändning.

Mot denna bakgrund avser det svenska ordförandeskapet att anordna ett seminarium där man kommer att fördjupa sig i frågor som rör hållbar livsmedelsproduktion och -konsumtion.

De nordiska länderna har en särskild ställning både gällande resistensläge och antibiotikaanvändning jämfört med många andra länder i Europa och internationellt. Det finns därför stora fördelar med utbyte av kunskap och praktisk erfarenhet mellan de nordiska länderna. Inom ramen för det nordiska samarbetet är det angeläget att aktörer inom human-, djur-, livsmedels- samt miljösektorn arbetar tillsammans dels för att behålla det goda resistensläget, dels för att fortsatt öka förutsättningarna för en låg antibiotikaanvändning. Sverige avser därför arrangera det fjärde nordiska expertmötet om antibiotikaresistens samt ett möte inom ramen för strategigruppen under 2018.

\section{Skog}

Det nordiska samarbetet på skogsområdet går till största del ut på att främja ett hållbart skogsbruk och se skogens 


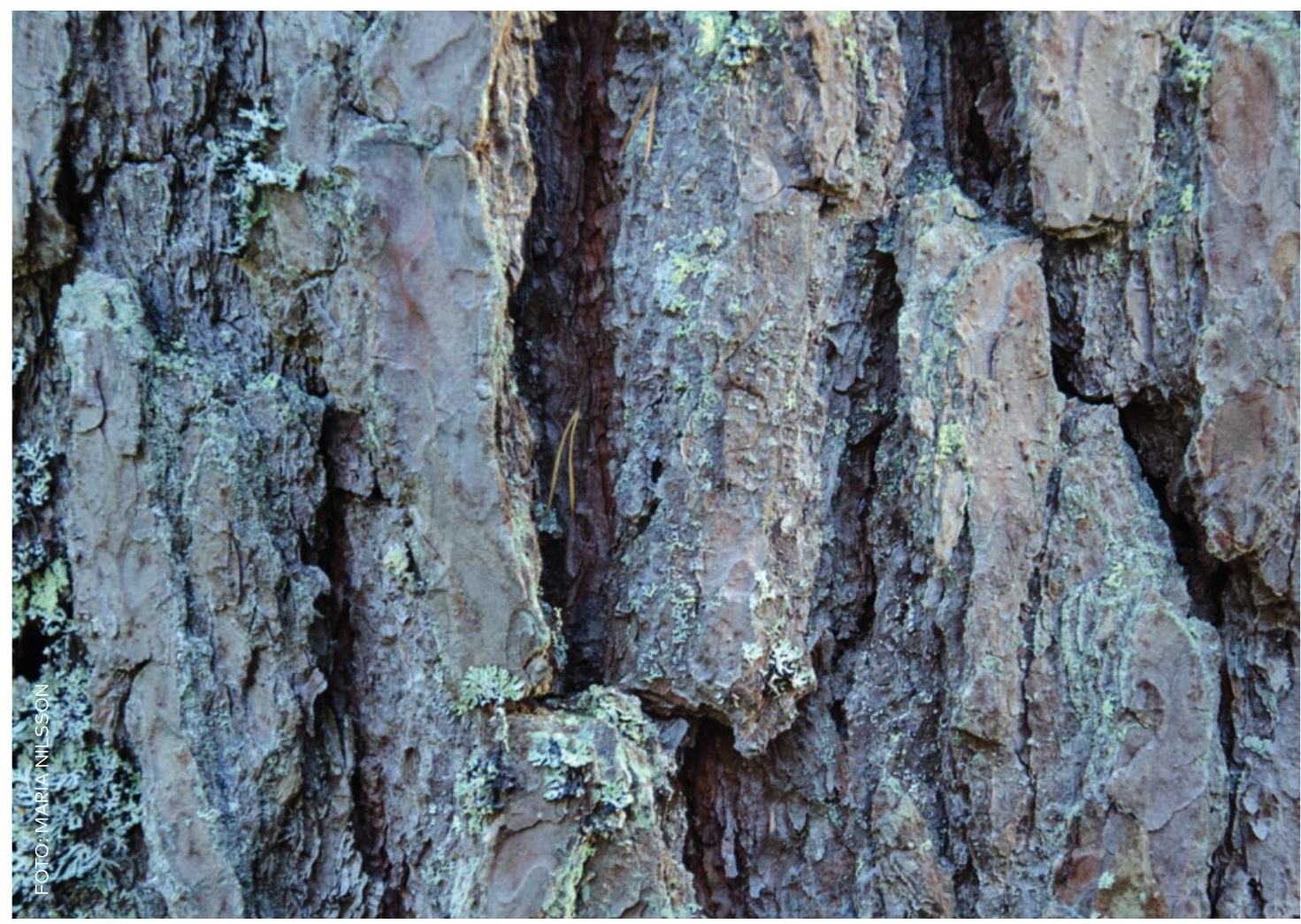

och skogsbrukets roll i en växande bioekonomi. Inom MR-FJLS har man på skogsområdet tagit fram en färdplan kallad Nordic Forest Solutions. Den bygger på Selfoss-deklarationen beslutad av de nordiska skogsministrarna 2008, och lyfter fram viktiga utmaningar och de lösningar som skogen kan bidra med. Dokumentet syftar till att stärka den nordiska rösten på regional, europeisk och global nivå. Den identifierar områden där samarbete inom nordisk skogssektor kan bidra med lösningar - Nordic Forest Solutions, baserade på samarbete mellan existerande plattformar. Dokumentet kan tjäna som en inspirationskälla för framtida implementering genom de nordiska institutionerna och olika intressenter i skogens hela värdekedja.

Genom förbättrat samarbete kan skogssektorn stärka sin röst och bidra till Nordic Forest Solutions inom och utom regionen.

Mot denna bakgrund finns det under det svenska ordförandeskapet anledning att fördjupa sig i frågor som rör skog eller skogsprodukter, som träbyggande med samarbetsområdet trä och design, nationella skogsprogram och det Boreala skogssamarbetet. 


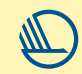

Nordisk ministerråd

Nordens Hus

Ved Stranden 18

DK-1061 København K

www.norden.org

Inom fiskerisamarbetet kommer fokus att ligga på att förverkliga potentialen inom blå bioekonomi. Med digitaliseringens möjligheter kommer det svenska ordförandeskapet för jordbrukssektorn att fokusera på områdena hållbar förvaltning av biologiska resurser, ökad konkurrensförmåga, resiliens och minskad klimatpåverkan från primärproduktionen samt diversifierad landsbygdsekonomi. Hälsosam och säker mat är i fokus. Det svenska ordförandeskapet vill fortsätta utveckla detta samarbete inom ramen för en hållbar utveckling. Under ordförandeskapet är frågor som rör skog eller skogsprodukter en prioritet.

Utmaningarna i hållbarhetsarbetet är till stor del globala, men lösningarna lokala. MR-FJLS har i sitt samarbetsprogram för 2017-2020 beslutat att man under perioden ska arbeta för att uppfylla FN:s mål för global utveckling. 